Research Article

\title{
Identification of Engine Inertia Parameters and System Dynamic Stiffness via In Situ Method
}

\author{
Chuanyan Xu (D), Xun Gong, Lixue Meng, and Aijuan Li \\ School of Automotive Engineering, Shandong Jiaotong University, Jinan 250023, China \\ Correspondence should be addressed to Chuanyan Xu; 254883652@qq.com
}

Received 8 May 2021; Accepted 31 July 2021; Published 11 August 2021

Academic Editor: Yuqing Zhou

Copyright (C) 2021 Chuanyan Xu et al. This is an open access article distributed under the Creative Commons Attribution License, which permits unrestricted use, distribution, and reproduction in any medium, provided the original work is properly cited.

\begin{abstract}
An in situ method is presented to identify ten engine inertia parameters and system dynamic stiffness from the frequency response functions. The ten engine inertia parameters and system dynamic stiffness are estimated from two distinct steps. The accuracy of the proposed technique is verified by finite element simulation, and then the generality is validated using an engine supported by a specially designed curved bar spring. The locations of the measure points on the results are also carefully investigated. The identification of system dynamic stiffness is validated comparing with the engine with an auxiliary plate, which shows good consistency with the results identified from the study.
\end{abstract}

\section{Introduction}

The identification of engine inertia parameters is important in the analysis of dynamic behaviour, suspension system optimization design, vibration attenuation and isolation, and engine fault diagnosis. During the dynamic structure design, the inertia parameters are regarded as known parameters, for example, when analysing the vehicle vibration noise due to the unbalance forces and moments caused by the engine, the engine is commonly simplified as a threedimensional model by setting inertia parameters. The inertia parameters of a rigid body directly affect the dynamic behaviour of the system; when there are errors in the identification of the inertia parameter, the dynamic characteristics of the structure will be affected inevitably; and a $5 \%$ error of the inertial parameters identification can lead to some order modal frequency reaches more than $1 \mathrm{~Hz}[1]$. Therefore, the accurate identification of inertia parameters is of great significance to engineering practice. Engines on the test bench and the actual vehicle are mounted by rubber suspension, from a practical application point of view; work efficiency is no less important than the accuracy of the test. It is quite necessary to develop a method to identify inertial parameters and system dynamic stiffness simultaneously for the engine mounting system.
The conventional techniques for parameters identification of the rigid body can be divided into two categories, i.e., time domain methods [2-7] and frequency domain methods. The frequency domain methods may be further subdivided into three categories: modal model method [8-10], residual inertia method [11-15], and direct system identification method $[16,17]$. The classical domain pendulum method is often timeconsuming due to repetitive configuration adjustments of a heavy target and complicated body such as an automotive powertrain. The classical residual inertia method must overhang the test rigid body and consider mass as a known parameter; in actual application, the mass is often unknown, and large structure weighing is difficult to achieve. The modal method and direct system identification methods are based on the orthogonality relationship between the mass matrix and six rigid body modes. In order to get the ideal $m$ rigid body modes, ideal spring constraints must be artificially added [18]. Unfortunately, in actual test, ideal boundary conditions are almost impossible to achieve. Thus, it has usually difficulty exciting all six rigid body modes at the same time due to the coupling of rigid body modes $[19,20]$; the identification accuracy is hard to guarantee. Vahid et al. [21] and Jeffrey et al. [22] provided methods to estimate the vehicle engine rigid body inertia properties based on in situ measurements. However, a quadratic integral is applied to calculate the mount reaction forces; 
when the second integral is executed, the unknown primitive value of the velocity and displacement must be set at zero, which can lead to greater identification errors. In addition, the maximum error in the literature [23] reaches $30 \%$. In recent years, the intelligent method is widely used in structural parameter analysis and diagnosis [24-26], and the firefly algorithm is used to identify inertial parameters of the powertrain mounting system from simulation. However, such a method requires experiments to verify its effectiveness [27].

Stiffness and damping characteristics are the most important parameters for predicting the dynamic characteristics of the structural system and isolating the vibration and noise of sources to reduce fatigue failure or damage caused by vibration $[28,29]$. Normally, the identification of the engine suspension system dynamic behaviour requires special experiments and special facilities [30]. In this paper, we provide a method to identify the dynamic stiffness of the suspension system in situ without a special experiment.

The main contributions of the paper are as follows. (1) An in situ identification method for engine inertia parameters and system dynamic stiffness is proposed. The method does not need to calculate the mount reaction force and avoid the error caused by the quadratic integral of acceleration. (2) The effects on the results due to the shaker location and response location are investigated.

\section{Identification Method}

2.1. Identification of the Inertia Properties. Since the natural frequency of a powertrain mounting system is commonly within $30 \mathrm{~Hz}$, the engine support system vibration model can be viewed as six degrees of freedom of vibration [19]. The equations of motion for the engine can be expressed as follows:

$$
\mathbf{M Q ̈}(t)+\mathbf{C Q}(t)+\mathbf{K Q}(t)=\mathbf{F}(t),
$$

where $\mathbf{M}$ is the mass matrix whose elements are the inertia parameters to be determined, $\mathbf{C}$ is the damping matrix, $\mathbf{K}$ is the stiffness matrix, $\mathbf{Q}$ is the generalized displacement vector, and $\mathbf{F}$ is the generalized force vector of origin $O$.

$$
\begin{aligned}
\underset{6 \times 6}{\mathbf{M}} & =\left[\begin{array}{cccccc}
m & 0 & 0 & 0 & m z_{c} & -m y_{c} \\
0 & m & 0 & -m z_{c} & 0 & m x_{c} \\
0 & 0 & m & m y_{c} & -m x_{c} & 0 \\
0 & -m z_{c} & m y_{c} & J_{x x o} & -J_{x y o} & -J_{x z o} \\
m z_{c} & 0 & -m x_{c} & -J_{x y o} & J_{y y o} & -J_{y z o} \\
-m y_{c} & m x_{c} & 0 & -J_{x z o} & -J_{y z o} & J_{z z o}
\end{array}\right], \\
\underset{6 \times 6}{K} & =\left[\begin{array}{llllll}
k_{x x} & k_{x y} & k_{x z} & k_{x \alpha} & k_{x \beta} & k_{x \gamma} \\
k_{y x} & k_{y y} & k_{y z} & k_{y \alpha} & k_{y \beta} & k_{y \gamma} \\
k_{z x} & k_{z y} & k_{z z} & k_{z \alpha} & k_{z \beta} & k_{z \gamma} \\
k_{\alpha x} & k_{\alpha y} & k_{\alpha z} & k_{\alpha \alpha} & k_{\alpha \beta} & k_{\alpha \gamma} \\
k_{\beta x} & k_{\beta y} & k_{\beta z} & k_{\beta \alpha} & k_{\beta \beta} & k_{\beta \gamma} \\
k_{\gamma x} & k_{\gamma y} & k_{\gamma z} & k_{\gamma \alpha} & k_{\gamma \beta} & k_{\gamma \gamma}
\end{array}\right],
\end{aligned}
$$

where $k_{x x}, k_{y y}$, and $k_{z z}$ are the total reciprocating stiffness of elastic support; $k_{x y}, k_{x z}$, and $k_{z y}$ are the coupling stiffness of elastic support; and $k_{\alpha \alpha}, k_{\beta \beta}$, and $k_{\gamma \gamma}$ are the rotary stiffness about the coordinate axis.

$$
\begin{gathered}
\underset{6 \times 1}{F}=\left\{\begin{array}{c}
F_{x} \\
F_{y} \\
F_{z} \\
M_{x} \\
M_{y} \\
M_{z}
\end{array}\right\}, \\
\underset{6 \times 1}{Q}=\left\{\begin{array}{c}
X_{o} \\
Y_{o} \\
Z_{o} \\
\alpha \\
\beta \\
\gamma
\end{array}\right\} .
\end{gathered}
$$

Both sides take Fourier transformation as follows:

$$
\left[\mathbf{M}-\frac{\mathbf{K}}{\omega^{2}}-\frac{j \mathbf{C}}{\omega}\right] \ddot{\mathbf{Q}}(f)=\mathbf{F}(f) .
$$

According to the coordinate transformation of the response and excitation points [14], the vibration equation of the engine due to $n$ excitation forces and $s$ measurement points can be obtained as follows:

$$
\left[\mathbf{M}-\frac{1}{\omega^{2}} \mathbf{K}^{*}\right] \mathbf{X}=\mathbf{T},
$$

where

$$
\mathbf{X}=\left(\mathbf{E}^{T} \mathbf{E}\right)^{-1} \mathbf{E}^{T} \mathbf{H},
$$

where $\mathbf{H}$ is the transfer function matrix, which can be obtained from the experiment test; $\mathbf{E}$ is the transpose matrix for response points; and $T$ is the transpose matrix for excitation points. The number of response points $s \geq 2$ is required (in three directions), so that the rank of matrix $\mathbf{E}$ is above 6 , and $\ddot{\mathbf{Q}}$ can be determined in a least-square sense. The number of excitation points must be equal to or greater than 6 , so matrix $\mathbf{M}$ can be calculated in a least-square sense. The locations of the sensors should have sufficient rigidity.

Transposing equation (5) and rearranging yield

$$
\mathbf{X}^{T} \mathbf{M}=\mathbf{T}^{T}+\frac{1}{\omega^{2}} \mathbf{X}^{T}\left(\mathbf{K}^{*}\right)^{T} .
$$

Equation (7) consists of 6 equations and 10 unknowns. In the frequency domain, the force and acceleration are generally complex quantities, so the real and imaginary parts can be separated to yield 12 equations with 10 unknowns

$$
\left[\begin{array}{c}
\operatorname{Re}\left\{\mathbf{X}^{T}\right\} \\
\operatorname{Im}\left\{\mathbf{X}^{T}\right\}
\end{array}\right] \mathbf{M}=\left[\begin{array}{c}
\operatorname{Re}\left\{\mathbf{T}^{T}+\frac{1}{\omega^{2}} \mathbf{X}^{T}\left(\mathbf{K}^{*}\right)^{T}\right\} \\
\operatorname{Im}\left\{\frac{1}{\omega^{2}} \mathbf{X}^{T}\left(\mathbf{K}^{*}\right)^{T}\right\}
\end{array}\right] .
$$


These 12 equations are not linearly independent, so additional equations must be generated to solve for $\mathbf{M}$. Although the frequency response function is a function of the frequency, with different values at each frequency line, the inertia parameters are constant. In addition, the frequency response function values of adjacent frequency lines are nearly identical, which implies that frequency lines must be selected sufficiently far apart to ensure linearly independent equations. The expanded equation is shown as follows:

$$
\mathbf{A M}=\mathbf{B},
$$

where

$$
\begin{aligned}
& \mathbf{A}=\left[\begin{array}{c}
\operatorname{Re}\left\{\mathbf{X}_{1}^{T}\right\} \\
\operatorname{Im}\left\{\mathbf{X}_{1}^{T}\right\} \\
\vdots \\
\operatorname{Re}\left\{\mathbf{X}_{r}^{T}\right\} \\
\operatorname{Im}\left\{\mathbf{X}_{r}^{T}\right\}
\end{array}\right], \\
& \mathbf{B}=\left[\begin{array}{c}
\operatorname{Re}\left\{\mathbf{X}_{1}^{T}+\frac{1}{\omega_{1}^{2}} \mathbf{X}_{1}^{T}\left(\mathbf{K}^{*}\right)^{\mathbf{T}}\right\} \\
\operatorname{Im}\left\{\frac{1}{\omega_{1}^{2}} \mathbf{X}_{1}^{T}\left(\mathbf{K}^{*}\right)^{\mathbf{T}}\right\} \\
\vdots \\
\operatorname{Re}\left\{\mathbf{X}_{r}^{T}+\frac{1}{\omega_{r}^{2}} \mathbf{X}_{r}^{T}\left(\mathbf{K}^{*}\right)^{\mathbf{T}}\right\} \\
\operatorname{Im}\left\{\frac{1}{\omega_{r}^{2}} \mathbf{X}_{r}^{T}\left(\mathbf{K}^{*}\right)^{\mathbf{T}}\right\}
\end{array}\right]
\end{aligned}
$$

Then, matrix $\mathbf{M}$ can be calculated in a least-square sense as follows:

$$
\mathbf{M}=\left(\mathbf{A}^{T} \mathbf{A}\right)^{-1} \mathbf{A}^{T} \mathbf{B}
$$

After mass matrix $\mathbf{M}$ has been determined, the ten inertia parameters can be obtained.

2.2. Identification of the System Dynamic Stiffness. Based on the identified mass matrix $\mathbf{M}$ and frequency response functions (FRFs) in the low-rigid-frequency domain, the system dynamic stiffness can be easily estimated.

Assuming that

$$
\mathbf{H}_{o}=\left(\mathbf{E}^{T} \mathbf{E}\right)^{-1} \mathbf{E}^{T} \mathbf{H}
$$

Then,

$$
\mathbf{K}^{*} \mathbf{H}_{o}=\omega^{2}\left(\mathbf{M} \mathbf{H}_{o}-\mathbf{T}\right) .
$$

Once mass matrix $\mathbf{M}$ is available, matrix $\mathbf{K}^{*}$ can be estimated using the pseudoinverse as follows:

$$
\mathbf{K}^{*}=\omega^{2}\left(\mathbf{M H}_{o}-\mathbf{T}\right) \mathbf{H}_{o}^{T}\left(\mathbf{H}_{o} \mathbf{H}_{o}^{T}\right)^{-1} .
$$

An iterative computation method is used to improve the inertia parameters identification accuracy. Consider the system dynamic stiffness identified by equation (14) as known parameters, we substitute equation (14) into equation (7), calculate the inertia parameters, and repeat this step until the identified inertia parameters converge. Thus, the effect of the rigid body modes on the identification of inertia parameters decreases.

\section{Numerical Study}

Mounts greatly vary in stiffness due to the manufacturing variability, temperature, and displacement. Thus, the identification of inertia parameters of a certain frequency line is not representative. To verify the generality of the method, a specially designed curved bar spring in Figure 1 is used to support a standard block (the mass is $160.6 \mathrm{~kg}$, and the density is $7.85 \times 10^{6} / \mathrm{m}^{3}$ ) simulated the engine (Figure 2). One end of the spring is attached to the standard block, while the other end is fixed by six degrees of freedom. The characteristics of the curved bar spring are as follows: (1) linearly elastic: the three directions of its local coordinate system are linear, and the coupling directions are also linear and (2) small damp: the damp of the spring is negligible.

The 4 response measurement points and 9 applied forces were selected for testing points. The FRFs of the block were measured with the sampling frequency of $2048 \mathrm{~Hz}$ and 512 sampling points by the structural Nastran FRF case module. The modulus of the FRFs is shown in Figure 3.

Figure 3 shows that the rigid body modes of the engine lie below $35 \mathrm{~Hz}$, and there is no coupling phenomenon. The first elastic resonance frequency is about $177 \mathrm{~Hz}$ with little amplitude; it is available to estimate the mass line from the measured FRFs. In addition, the dynamic stiffness of the support system has little effect on the mass line; it is negligible from engineering practice.

In general, more testing points than required are selected to ensure a good result. By equation (12), $\mathbf{H}_{o}$ can be calculated; then the FRFs of the $j^{\text {th }}$ frequency line $\mathbf{H}_{j}$ can be derived by inverse operation $\mathbf{H}_{j}^{\prime}$. The difference between $\mathbf{H}_{j}$ and $\mathbf{H}_{j}^{\prime}$ can be used to determine the error of the results, which can be expressed as follows:

$$
\operatorname{err}_{j}=\left|\mathrm{H}_{j}-\mathbf{H}_{j}^{\prime}\right| \text {. }
$$

The total error can be calculated as follows:

$$
\text { err }=\frac{1}{3 \times N \times P} \sum_{j=1}^{3 \times N \times P}\left|H_{j}-\mathbf{H}_{j}^{\prime}\right| .
$$

To improve the inertia parameters identification accuracy, the error should remain in a certain range, that is, $\operatorname{err}_{j}<\operatorname{err} \times$ level (level, the initial value), or $\mathbf{H}_{j}$ should be eliminated. Since equation (11) uses a least-square method, the rank of matrix $\mathbf{T}$ should be full, and the condition 


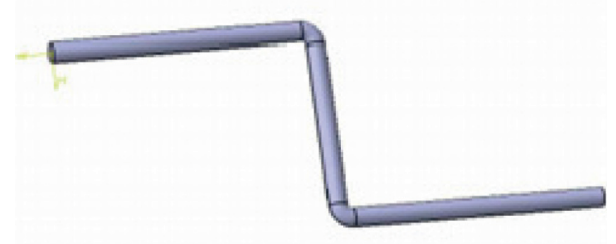

FIgURE 1: Curve bar spring.

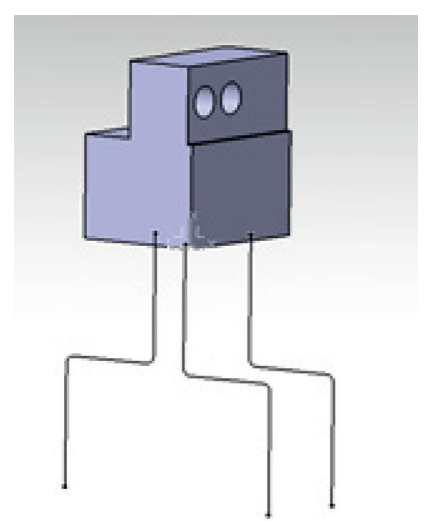

Figure 2: Standard block supported by curve bar springs.

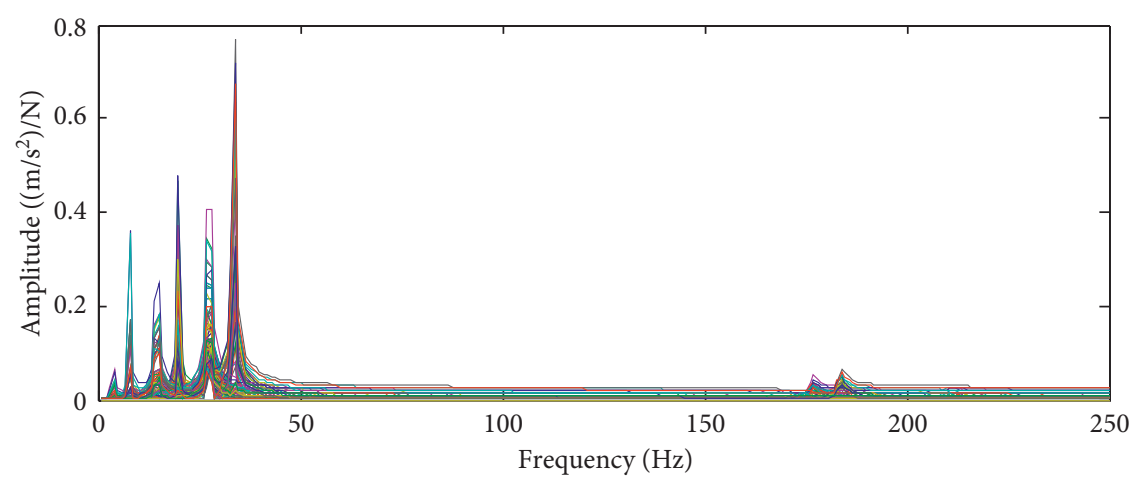

FIGURE 3: Modulus of the FRFs.

number con of matrix $\mathbf{T}$ should be lower than 20 [20]. In conclusion, there are three conditions to select the frequency lines of the FRFs: (1) $\operatorname{err}_{j}<\operatorname{err} \times \operatorname{level},(2) \operatorname{rank}(\mathbf{T})=6$, and (3) Cond $(\mathbf{T})<$ con. The response points are selected in similar manners.

The frequency bands from $90 \mathrm{~Hz}$ up to $150 \mathrm{~Hz}$ were selected to identify the ten inertia parameters by equation (11). The identified standard block inertia parameters are presented in Table 1 with a comparison to the finite element simulation results, and the stiffness of the curve bar spring is shown in Table 2. The maximum inertia parameters error is $1.74 \%$ for $x_{c}$; the element error of the matrix $\mathbf{K}$ is within $2 \%$; and the identified results are consistent with the theory values. In addition, the linear characteristics of the curve bar spring verify the generality of the method.
The six rigid mode shapes have a relatively large magnitude; it is necessary to study their effect on the identification of inertia parameters, so as to see the dynamic behaviour of the engine support system. To ignore the effect of rigid mode shapes, the inertia parameters can be computed using the method in the literature [14], that is, the swing method. The residual inertia method was used to estimate the inertia parameters. To consider the effect of rigid mode shapes, substitute the FEM system stiffness into equation (5); the frequency bands from $90 \mathrm{~Hz}$ up to $150 \mathrm{~Hz}$ were used to identify the ten inertia parameters. The results are shown in Table 3 . The rigid mode shapes have little effect on the estimation of inertia parameters. Since the first elastic mode shapes have a very small magnitude, the inertia parameters are basically unchanged. Both the six rigid and first 
TABLE 1: Standard block inertia parameters.

\begin{tabular}{lcccc}
\hline & & FEM & Proposed method & Error (\%) \\
\hline Mass $(\mathrm{kg})$ & $m$ & 161.2 & 163.3 & -1.28 \\
\hline \multirow{3}{*}{ Centre of gravity $(\mathrm{mm})$} & $x_{c}$ & 147.0 & 144.4 & 1.74 \\
& $y_{c}$ & 152.3 & 112.7 & 0.03 \\
\hline \multirow{3}{*}{ Moment of inertia $\left(\mathrm{kg} \cdot \mathrm{m}^{2}\right)$} & $z_{c}$ & 112.9 & 7.87 & 0.15 \\
& $J_{x}$ & 7.77 & 7.82 & -1.31 \\
& $J_{y}$ & 7.74 & 10.02 & -0.99 \\
Product $\left(\mathrm{kg} \cdot \mathrm{m}^{2}\right)$ & $J_{z}$ & 9.90 & 3.64 & 0.44 \\
& $J_{x y}$ & 3.66 & 2.79 & -1.11 \\
& $J_{x z}$ & 2.76 & 2.41 & 0.59 \\
\hline
\end{tabular}

TABLE 2: Identified system stiffness of the curve bar spring.

\begin{tabular}{|c|c|c|c|c|c|c|c|}
\hline & Direction & $x$ & $y$ & $z$ & $\alpha$ & $\beta$ & $\gamma$ \\
\hline \multirow{6}{*}{ FEM system stiffness $(\mathrm{N} / \mathrm{m})$} & $x$ & 2695193 & 0 & 536118.7 & 0 & 44461.07 & 0 \\
\hline & $y$ & 0 & 275302 & 0 & 9247.395 & 0 & -69097.7 \\
\hline & $z$ & 536118.7 & 0 & 1416128 & 0 & 85055.21 & 0 \\
\hline & $\alpha$ & 0 & 9247.395 & 0 & 22965.87 & 0 & -13059.3 \\
\hline & $\beta$ & 44461.07 & 0 & 85055.21 & 0 & 37323.23 & 0 \\
\hline & $\gamma$ & 0 & -69097.7 & 0 & -13059.3 & 0 & 41700.41 \\
\hline \multirow{6}{*}{ Estimated system stiffness $(\mathrm{N} / \mathrm{m})$} & $x$ & 2686950.3 & -67.8 & 536001.9 & 80395.7 & 313059.6 & -403005.1 \\
\hline & $y$ & 61.9 & 272706.3 & 63.0 & -18142.7 & 15.7 & -68023.4 \\
\hline & $z$ & 539171.3 & -36.3 & 1419722.6 & 212926.3 & 139301.4 & -80845.6 \\
\hline & $\alpha$ & 80788.2 & -18181.8 & 212693.0 & 55748.0 & 20843.2 & -18336.2 \\
\hline & $\beta$ & 313161.1 & 4.2 & 138468.0 & 20756.3 & 73034.6 & -46970.4 \\
\hline & $\gamma$ & -403015.0 & -68262.8 & -80467.7 & -18264.8 & -46967.9 & 101906.0 \\
\hline \multirow{6}{*}{ Error (\%) } & $x$ & 0.31 & - & 0.02 & 0.03 & 0.29 & 0.32 \\
\hline & $y$ & - & 0.94 & - & 0.77 & - & 1.55 \\
\hline & $z$ & -0.57 & - & -0.25 & -0.24 & -0.46 & -0.53 \\
\hline & $\alpha$ & -0.46 & 0.55 & -0.13 & -0.03 & -0.21 & -0.68 \\
\hline & $\beta$ & 0.26 & - & 0.14 & 0.21 & 0.18 & 0.27 \\
\hline & $\gamma$ & 0.31 & 1.21 & -0.06 & -0.29 & 0.27 & 0.43 \\
\hline
\end{tabular}

TABLE 3: Effects of rigid shapes on the identification of inertia parameters.

\begin{tabular}{|c|c|c|c|c|c|c|}
\hline & & Theory & Ignore rigid shapes & Error (\%) & Consider rigid shapes & Error (\%) \\
\hline Mass (kg) & $m$ & 160.6 & 161.3 & -0.44 & 163.7 & -0.44 \\
\hline \multirow{3}{*}{ Centre of gravity (mm) } & $x_{c}$ & 147.0 & 147.0 & 0.00 & 144.8 & 0.00 \\
\hline & $y_{c}$ & 152.3 & 151.1 & 0.79 & 148.4 & 0.79 \\
\hline & $z_{c}$ & 112.9 & 112.9 & 0.00 & 111 & 0.00 \\
\hline \multirow{3}{*}{ Moment of inertia $\left(\mathrm{kg} \cdot \mathrm{m}^{2}\right)$} & $J_{x}$ & 7.74 & 7.79 & -0.65 & 7.78 & -0.65 \\
\hline & $J_{y}$ & 7.71 & 7.70 & 0.13 & 7.68 & 0.13 \\
\hline & $J_{z}$ & 9.86 & 9.89 & -0.30 & 9.87 & -0.30 \\
\hline \multirow{3}{*}{ Product $\left(\mathrm{kg} \cdot \mathrm{m}^{2}\right)$} & $J_{x y}$ & 3.64 & 3.65 & -0.27 & 3.65 & -0.27 \\
\hline & $J_{x z}$ & 2.75 & 2.72 & 1.09 & 2.71 & 1.09 \\
\hline & $J_{y z}$ & 2.42 & 2.38 & 1.65 & 2.38 & 1.65 \\
\hline
\end{tabular}

elastic mode shapes can be ignored from a practical application point of view.

\section{Errors of the Testing Point Location Effect}

Since the testing point locations are essential input parameters for the algorithm, random errors were added to understand the sensibility of the method to location errors in this step. One hundred simulation runs were performed for each random error. The errors introduced into the inertia parameters are shown in Figure 4, and the excitation and response location errors introduced into the system stiffness are presented in Tables 4 and 5, respectively.

The errors in the locations of test points have almost no influence on the estimated mass. Both errors in other properties increase with the increase in the testing error. Approximately 4\% error is introduced by an error in the excitation locations, and approximately 9\% error is introduced by an error in the response locations. From Tables 4 and 5 , we can see that the error has a relatively larger effect 


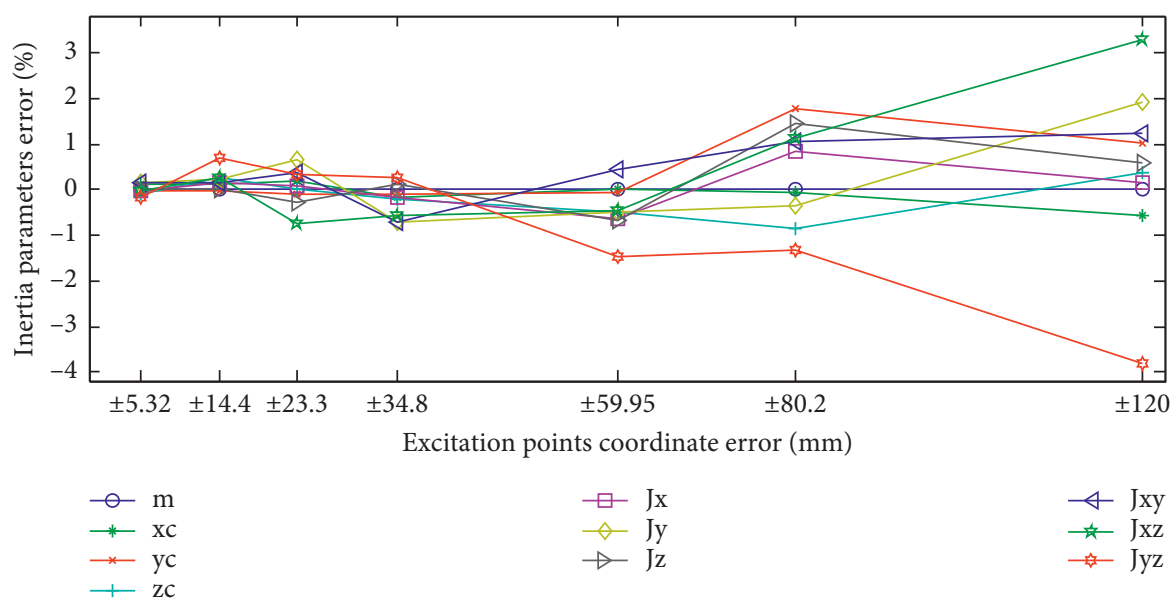

(a)

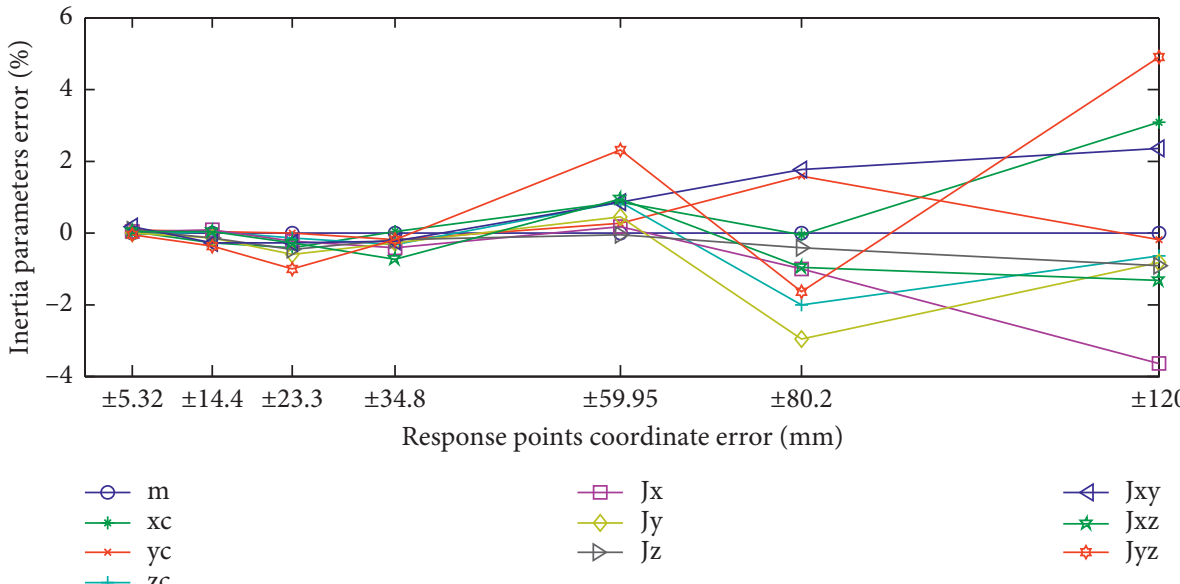

(b)

FIgURE 4: Sensitivity of inertia parameter to location errors: (a) excitation locations and (b) response locations.

TABLE 4: Sensitivity of the method to system stiffness errors at excitation locations.

\begin{tabular}{lccccccc}
\hline & Direction & $x$ & $y$ & $z$ & $\alpha$ & $\beta$ & $\gamma$ \\
\hline & $x$ & 2688379.0 & 308.4 & 537109.7 & 80584.8 & 313371.1 & -403403.0 \\
& $y$ & -260.8 & 272125.0 & -652.6 & -18363.7 & -124.8 & -67640.9 \\
Estimated stiffness $(\mathrm{K} / \mathrm{m})$ with error $\pm 34.8 \mathrm{~mm}$ & $z$ & 538223.5 & 53.0 & 1417243.0 & 212655.4 & 138738.3 & -80782.5 \\
& $\alpha$ & 80499.8 & -18736.8 & 211808.6 & 55768.4 & 20651.1 & -18095.9 \\
& $\beta$ & 314727.8 & -155.5 & 142674.1 & 21328.5 & 73933.7 & -47109.5 \\
& $\gamma$ & -403446.0 & -66291.1 & -80384.6 & -17941.4 & -46977.6 & 100948.6 \\
\hline & $x$ & -0.25 & - & 0.18 & 0.21 & -0.19 & -0.22 \\
Estimated error (\%) & $y$ & - & -1.15 & - & 0.44 & - & -2.11 \\
& $z$ & 0.39 & - & 0.08 & 0.11 & 0.05 & 0.45 \\
& $\alpha$ & 0.10 & 2.48 & -0.29 & 0.06 & -0.72 & -0.64 \\
& $\beta$ & 0.24 & - & 2.89 & 2.54 & 1.05 & 0.03 \\
& $\gamma$ & -0.21 & -4.06 & -0.04 & -1.49 & -0.25 & -1.36 \\
\hline
\end{tabular}


TABle 4: Continued.

\begin{tabular}{|c|c|c|c|c|c|c|c|}
\hline & Direction & $x$ & $y$ & $z$ & $\alpha$ & $\beta$ & $\gamma$ \\
\hline \multirow{6}{*}{ Estimated error (\%) } & $x$ & -0.24 & - & 0.16 & 0.18 & -0.20 & -0.21 \\
\hline & $y$ & - & -1.16 & - & 0.39 & - & -2.12 \\
\hline & $z$ & 0.39 & - & 0.08 & 0.10 & 0.04 & 0.44 \\
\hline & $\alpha$ & 0.74 & -3.97 & 0.24 & -1.21 & 0.24 & 1.01 \\
\hline & $\beta$ & 0.07 & - & 1.42 & 1.41 & 0.47 & 1.23 \\
\hline & $\gamma$ & 0.10 & -1.04 & 5.08 & 5.78 & 1.55 & 0.02 \\
\hline
\end{tabular}

TABLE 5: Sensitivity of the method to system stiffness errors in response locations.

\begin{tabular}{|c|c|c|c|c|c|c|c|}
\hline & Direction & $x$ & $y$ & $z$ & $\alpha$ & $\beta$ & $\gamma$ \\
\hline \multirow{12}{*}{ Random error $\pm 34.8 \mathrm{~mm}$} & $x$ & 2687089.0 & -49.4 & 534515.0 & 79808.6 & 312370.9 & -400879.0 \\
\hline & $y$ & -460.3 & 272380.3 & -820.9 & -17882.0 & -362.8 & -68551.1 \\
\hline & $z$ & 538707.6 & 555.9 & 1419494.0 & 211825.7 & 141596.3 & -80095.5 \\
\hline & $\alpha$ & 80841.6 & -17496.1 & 213273.3 & 55795.1 & 21209.0 & -18439.5 \\
\hline & $\beta$ & 311702.6 & -33.8 & 138302.0 & 20606.6 & 73283.5 & -46386.5 \\
\hline & $\gamma$ & -400960.0 & -68279.8 & -79754.0 & -18304.2 & -46517.9 & 101827.6 \\
\hline & $x$ & -0.3 & - & -0.3 & -0.76 & -0.51 & -0.84 \\
\hline & $y$ & - & -1.06 & - & -2.19 & - & -0.79 \\
\hline & $z$ & 0.48 & - & 0.24 & -0.28 & 2.11 & -0.40 \\
\hline & $\alpha$ & 0.53 & -4.30 & 0.40 & 0.11 & 1.97 & 1.25 \\
\hline & $\beta$ & -0.73 & - & -0.26 & -0.93 & 0.16 & -1.51 \\
\hline & $\gamma$ & -0.82 & -1.18 & -0.83 & 0.50 & -1.23 & -0.50 \\
\hline \multirow{6}{*}{ Random error $\pm 120 \mathrm{~mm}$} & $x$ & 2687577.0 & -863.8 & 533317.9 & 80772.6 & 326156.1 & -411843.0 \\
\hline & $y$ & -1342.0 & 269013.3 & 955.6 & -16104.3 & -366.2 & -79734.5 \\
\hline & $z$ & 535032.0 & -4586.7 & 1405268.0 & 211346.6 & 177723.6 & -88411.0 \\
\hline & $\alpha$ & 81899.9 & -18308.2 & 214197.9 & 61077.6 & 27131.7 & -21016.2 \\
\hline & $\beta$ & 312780.1 & -1596.4 & 135979.4 & 20503.2 & 82414.3 & -48248.2 \\
\hline & $\gamma$ & -407703.0 & -69072.3 & -81083.1 & -20979.8 & -48705.7 & 113786.3 \\
\hline \multirow{6}{*}{ Estimated error (\%) } & $x$ & -0.28 & - & -0.52 & 0.44 & 3.88 & 1.87 \\
\hline & $y$ & - & -2.28 & - & -11.92 & - & 15.39 \\
\hline & $z$ & -0.20 & - & -0.77 & -0.50 & 28.17 & 9.94 \\
\hline & $\alpha$ & 1.84 & 0.14 & 0.84 & 9.59 & 30.44 & 15.40 \\
\hline & $\beta$ & -0.38 & - & -1.94 & -1.43 & 12.64 & 2.44 \\
\hline & $\gamma$ & 0.85 & -0.04 & 0.83 & 15.20 & 3.42 & 11.18 \\
\hline
\end{tabular}

on the estimated system dynamic stiffness, especially on the coupling stiffness; when the random error is in the range of $[-120,120]$, the estimated error on the coupling stiffness is $30.44 \%$. As shown, care must be taken in measuring geometry to avoid incorrect results. The units of the elements of the stiffness matrix are the corresponding generalized force divided by the generalized displacement.

\section{Experiments}

5.1. Curve Bar Spring Engine System. The test engine was supported by 3 specially designed curve bar springs shown in Figure 5. Here, 4 response points and 18 excitation points were taken into account. The coordinates of test points were measured by the $3 \mathrm{D}$ coordinate measuring apparatus.

The FRFs were measured with the sampling frequency of $1024 \mathrm{~Hz}$ and 1024 sampling points. The modulus of the FRFs for 4 response points and 3 of 18 excitation points are presented in Figure 6 . We can see that all six rigid body modes are excited within $30 \mathrm{~Hz}$, and the first elastic resonance frequency is approximately $118.5 \mathrm{~Hz}$. The FRFs and the corresponding coherence functions for response point 1 are shown in Figure 7 . The values of the coherent coefficients for the three directions are all greater than 0.8 , which verifies the reliability of the experiment.

The coordinate transformation of the test points [14] is valid only when the rigidity condition is satisfied. In this section, the measured and calculated FRFs were compared at the fourth accelerometer to check the rigidity of the engine. According to coordinate transformation, the FRFs of the fourth accelerometer can be calculated by the other three accelerometers, that is, Acc1, Acc2, and Acc3. As shown in Figure 8, the calculated FRFs agree well with the measured FRFs within $100 \mathrm{~Hz}$, which verified the rigidity of the engine.

The frequency bands from $60 \mathrm{~Hz}$ to $85 \mathrm{~Hz}$ were used to identify the 10 inertia parameters by equation (11) (Table 6). Then, the FRFs from $3 \mathrm{~Hz}$ to $35 \mathrm{~Hz}$ were used to identify the curve bar spring stiffness in Table 7 . The inertia parameters of the engine were also computed by the swing method [16], for comparison. The proposed method can identify the engine inertia method under normal installation conditions (in situ), while the swing method must remove the engine from the support infrastructure to ensure free-free boundary conditions. 

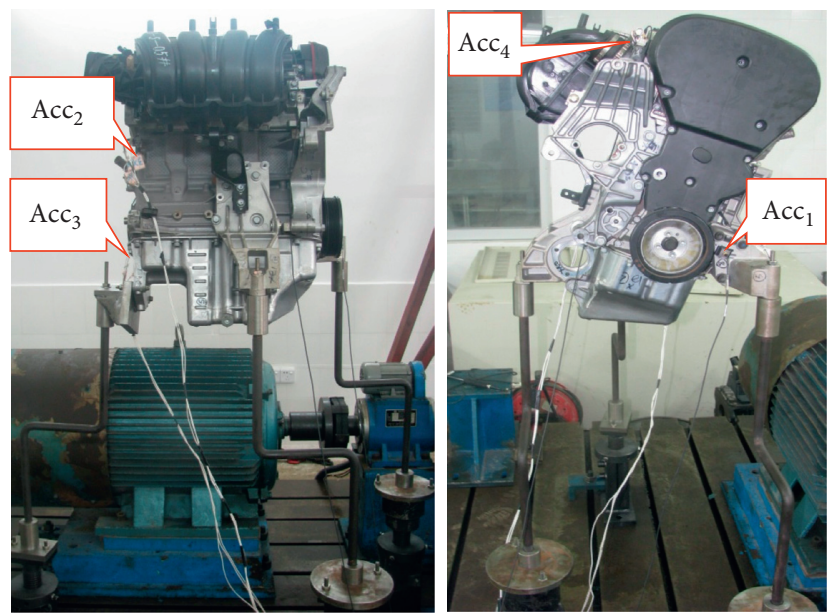

FIGURE 5: Test engine supported by curve bar springs.

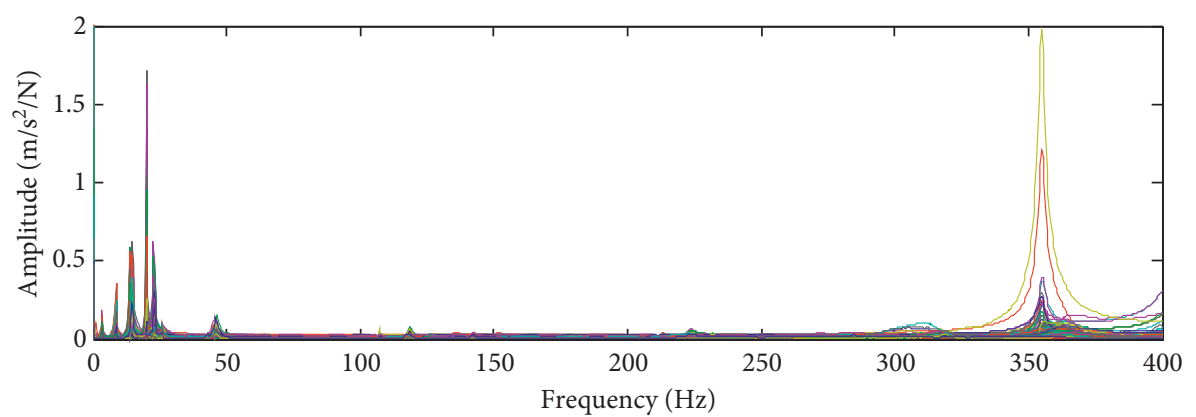

FIGURE 6: Amplitude-frequency response for response measurement points and applied forces.

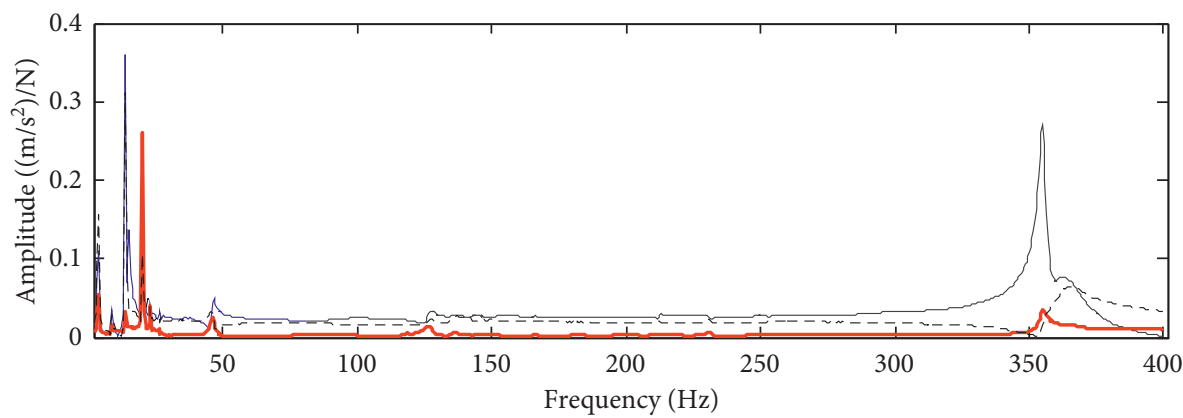

(a)

FIgURE 7: Continued. 


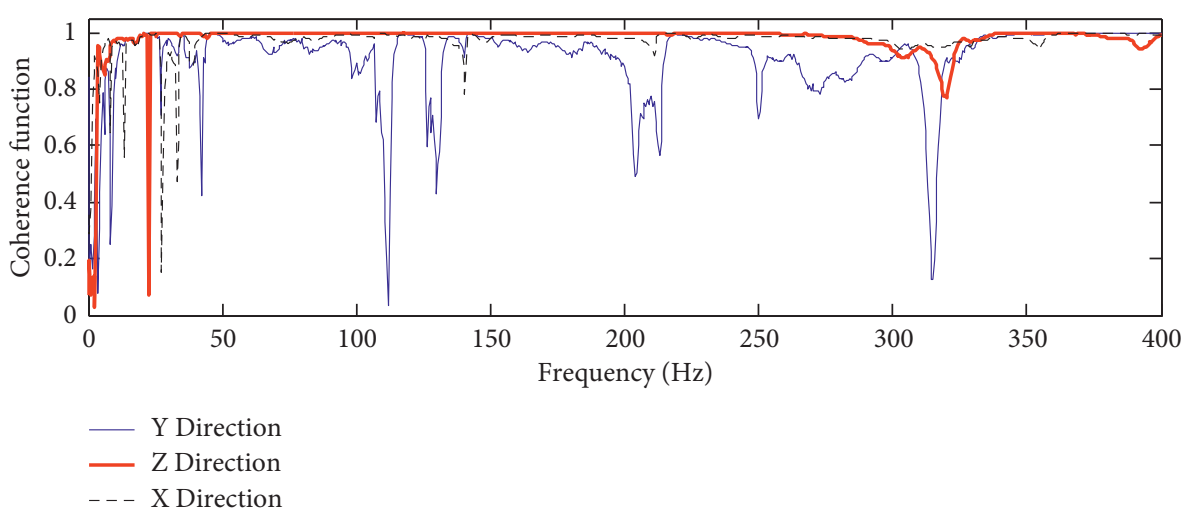

(b)

FIguRE 7: Example of the test FRFs (excitation: F17; response: Acc3): (a) FRF and (b) coherence.

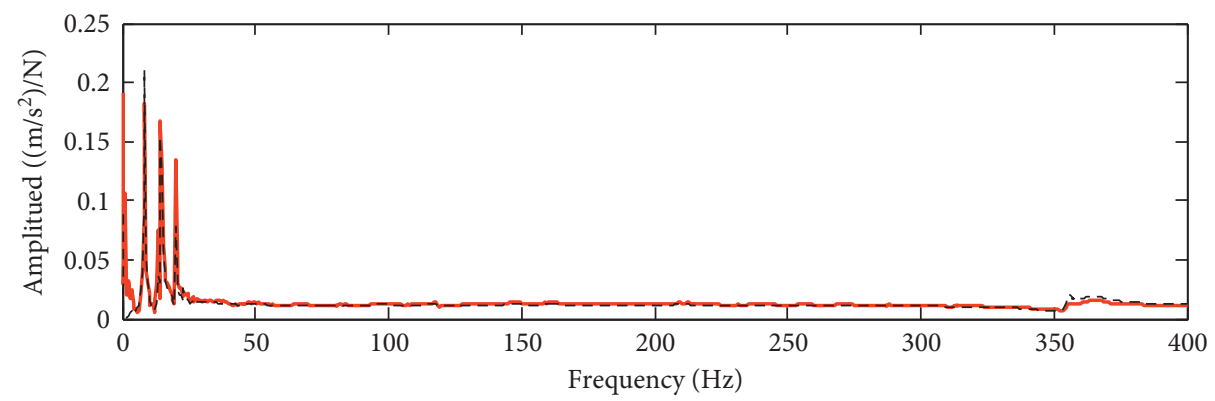

- Measured

- - Calculated

(a)

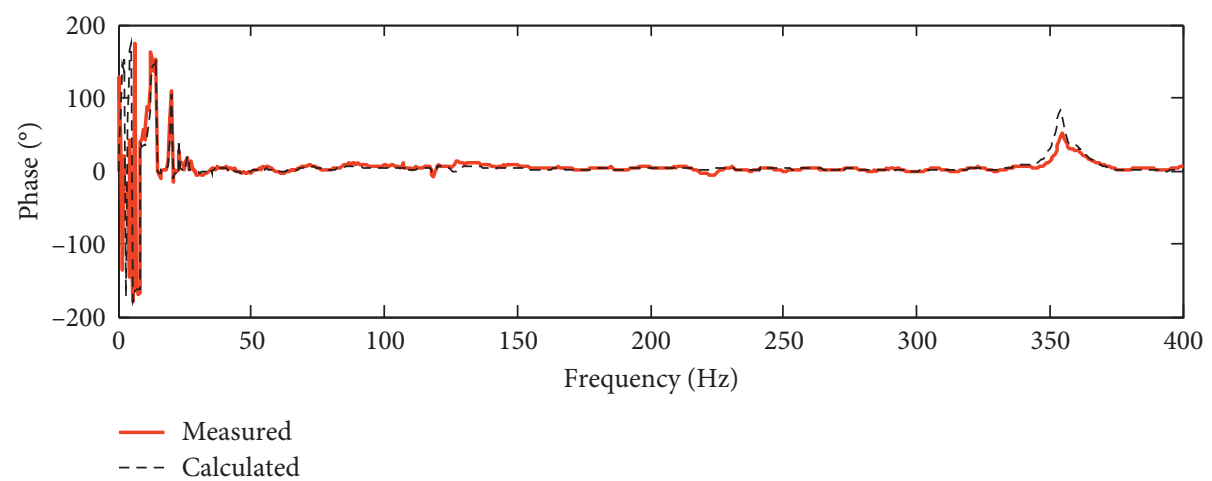

(b)

FIgURE 8: Rigidity check of the engine: (a) amplitude and (b) phase.

TABLE 6: Identified inertia parameters of the engine curve bar spring system.

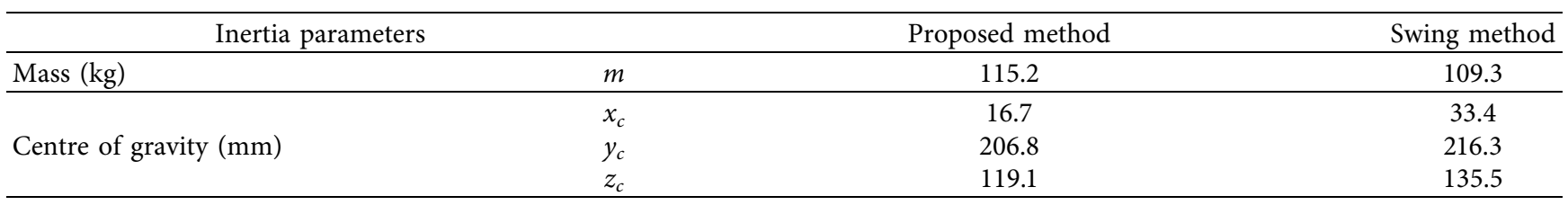


TABLE 6: Continued.

\begin{tabular}{lccc}
\hline \multicolumn{1}{c}{ Inertia parameters } & & Proposed method & Swing method \\
\hline \multirow{3}{*}{ Moment of inertia $\left(\mathrm{kg} \cdot \mathrm{m}^{2}\right)$} & $J_{x}$ & 11.52 & 11.62 \\
& $J_{y}$ & 5.50 & 5.42 \\
& $J_{z}$ & 8.80 & 8.46 \\
\hline \multirow{3}{*}{ Product $\left(\mathrm{kg} \cdot \mathrm{m}^{2}\right)$} & $J_{x y}$ & 0.27 & 0.03 \\
& $J_{x z}$ & 3.25 & 3.31 \\
& $J_{y z}$ & 0.23 & 0.12 \\
\hline
\end{tabular}

TABLE 7: Identified system stiffness of the engine supported by curve bar springs.

\begin{tabular}{|c|c|c|c|c|c|c|c|}
\hline & Direction & $x$ & $y$ & $z$ & $\alpha$ & $\beta$ & $\gamma$ \\
\hline \multirow{6}{*}{ Identified system stiffness $(\mathrm{N} / \mathrm{m})$} & $x$ & 290120.7 & 48337.8 & 386771.5 & 116531.3 & -22822.5 & -52696.2 \\
\hline & $y$ & 70933.0 & 395010.3 & 137520.8 & -10216.1 & -16877.2 & 20108.6 \\
\hline & $z$ & 553817.9 & 77824.8 & 1160978.8 & 268614.3 & 16786.5 & -124765.4 \\
\hline & $\alpha$ & 150337.5 & -14657.5 & 278525.7 & 133840.1 & 15069.3 & -44197.4 \\
\hline & $\beta$ & -57322.6 & -10786.8 & -35724.6 & 11531.1 & 64754.8 & 9857.5 \\
\hline & $\gamma$ & -47982.5 & 20608.0 & -89536.5 & -38565.4 & -1114.0 & 31575.3 \\
\hline
\end{tabular}

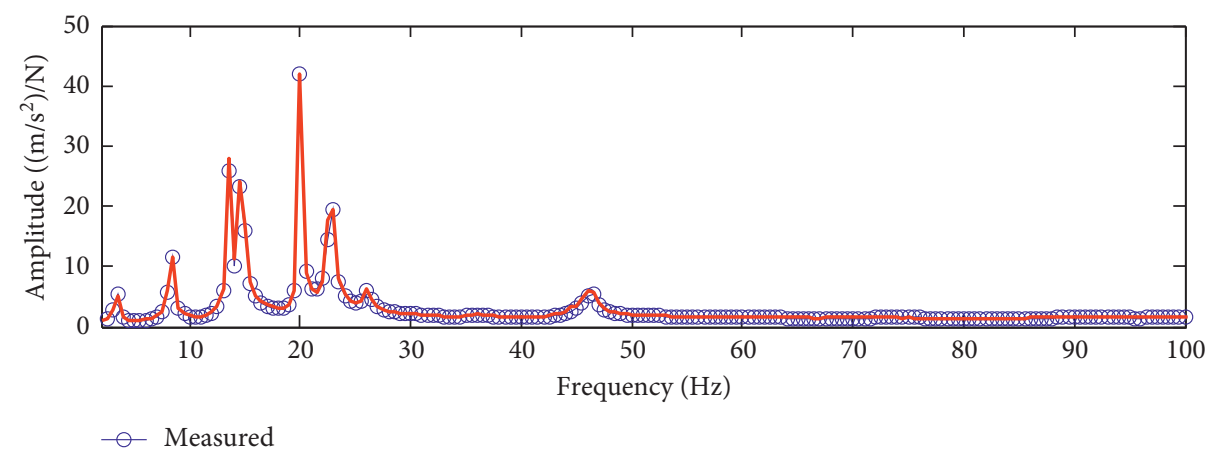

FIGURE 9: Modulus of the measured and calculated FRFs.
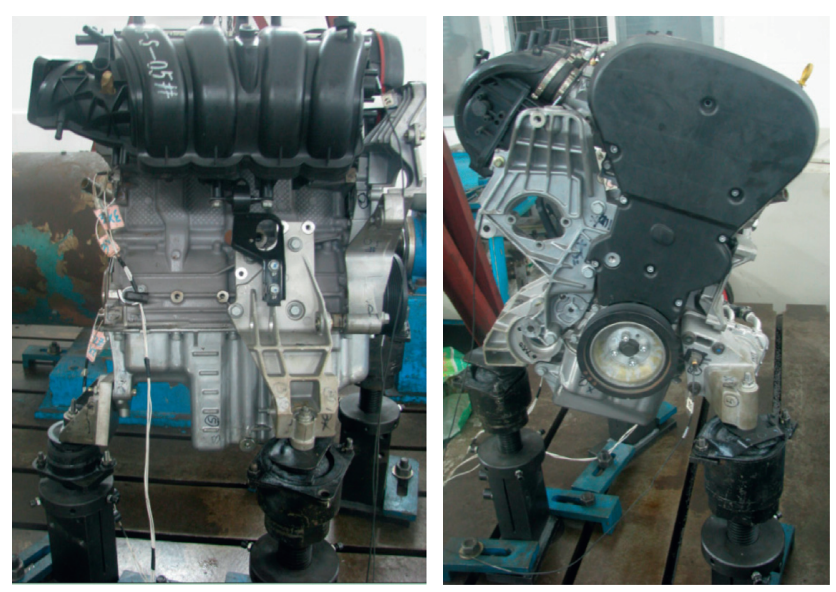

FIgUre 10: Test engine supported by the mount.

Since the engine and curve bar springs were connected through 3 switchover pieces $(0.81 \mathrm{~kg} \times 3)$ and an auxiliary plate (Figure 5), the identified engine mass was somewhat larger than the swing method estimated. In addition, the centre of gravity should reduce in value due to the effect of the switchover pieces $(0.81 \mathrm{~kg} \times 3)$ and an auxiliary plate compared with the swing method, and the results are consistent with the trend. The identified results of the proposed method are close to the results from the swing method. The stiffness values estimated from the presented method and extracted by the finite element simulation have a bias because: (1) there is machining error, (2) the three curve 


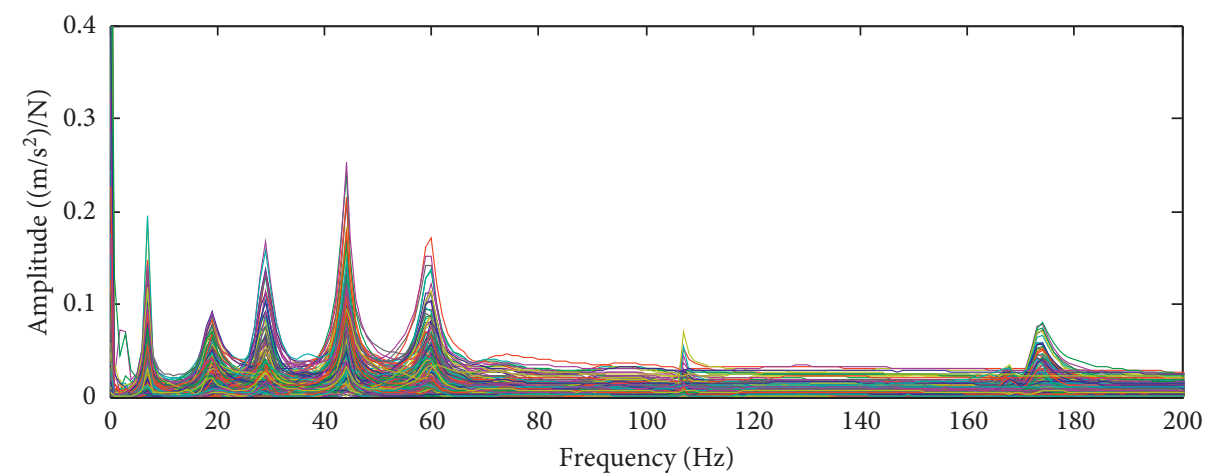

FIGURE 11: FRFs for all measurement points of the engine supported by the mount.

TABLE 8: Identified inertia parameters of the powertrain mount system.

\begin{tabular}{lccc}
\hline \multicolumn{1}{c}{ Inertia parameters } & & Proposed method & Swing method \\
\hline Mass $(\mathrm{kg})$ & $m$ & 110.8 & 109.3 \\
\hline \multirow{3}{*}{ Centre of gravity $(\mathrm{mm})$} & $x_{c}$ & 19.5 & 33.4 \\
& $y_{c}$ & 208.1 & 216.3 \\
& $z_{c}$ & 134.2 & 135.5 \\
\multirow{3}{*}{ Moment of inertia $\left(\mathrm{kg} \cdot \mathrm{m}^{2}\right)$} & $J_{x}$ & 11.56 & 11.62 \\
& $J_{y}$ & 5.61 & 5.42 \\
& $J_{z}$ & 8.01 & 8.46 \\
\hline \multirow{3}{*}{ Product $\left(\mathrm{kg} \cdot \mathrm{m}^{2}\right)$} & $J_{x y}$ & 0.34 & 0.56 \\
& $J_{x z}$ & 3.36 & 3.31 \\
& $J_{y z}$ & 0.26 & 0.15 \\
\hline
\end{tabular}

TABLE 9: Identified system dynamic stiffness of the powertrain mount system.

\begin{tabular}{|c|c|c|c|c|c|c|c|}
\hline & Direction & $x$ & $y$ & $z$ & $\alpha$ & $\beta$ & $\gamma$ \\
\hline \multirow{6}{*}{ System stiffness $(\mathrm{N} / \mathrm{m})$} & $x$ & 1490171.8 & -62047.3 & -363210.4 & -101692.6 & -245141.7 & -341731.1 \\
\hline & $y$ & 254.8 & 1910981.1 & -776855.1 & 199150.6 & 241490.1 & 259257.6 \\
\hline & $z$ & -547878.2 & -781461.8 & 4635226.6 & 1067626.9 & -694916.0 & -11255.6 \\
\hline & $\alpha$ & -119562.5 & 378584.3 & 1195191.6 & 436581.8 & -175183.9 & 90437.8 \\
\hline & $\beta$ & -265289.7 & 223319.6 & -697592.1 & -143398.3 & 222587.3 & 92242.3 \\
\hline & $\gamma$ & -369934.7 & 273163.7 & -63350.4 & 37893.5 & 86895.9 & 174911.2 \\
\hline \multirow{6}{*}{ System damp $(\mathrm{N} \cdot \mathrm{s} / \mathrm{m})$} & $x$ & 121371.1 & -19433.4 & 32809.8 & 19086.0 & 18288.5 & -24051.3 \\
\hline & $y$ & -58827.4 & 189173.6 & -95132.9 & -4759.9 & 18617.5 & 48450.6 \\
\hline & $z$ & 171024.9 & -213459.0 & 651576.1 & 158276.4 & -101082.1 & -91967.9 \\
\hline & $\alpha$ & 72740.8 & -44961.6 & 232898.8 & 57961.3 & -25358.0 & -34826.9 \\
\hline & $\beta$ & -39033.1 & 59188.1 & -88440.0 & -13369.6 & 31634.4 & 14076.3 \\
\hline & $\gamma$ & -37373.0 & 31182.6 & -30948.1 & -9501.8 & -4297.2 & 16228.2 \\
\hline
\end{tabular}

bar springs do not have exactly identical stiffness, and (3) the spring stiffness has a certain degree of nonlinearity.

Once the inertia parameters and system dynamic stiffness are known, the FRFs corresponding to the measured FRFs can be calculated. Comparing the sum of all calculated FRFs with the measured values, we find that the two FRFs have consistent moduli, as shown in Figure 9, which verifies the consistency of the identified results. Hereafter, if there is no specific declaration, the same method is utilized.

5.2. Mount Engine System. Here, the engine was supported by three mounts as shown in Figure 10. The engine and measuring points are identical to those in Figure 5. Similar steps to estimate the inertia parameters and system dynamic stiffness are applied in this section. The signals were collected with the sampling frequency of $256 \mathrm{~Hz}$ and 1024 points. The moduli of the calculated FRFs for all points are shown in Figure 11.

The coherent coefficients are greater than 0.8 , and the rigidity condition of the engine holds within $100 \mathrm{~Hz}$. The identified inertia parameters and system dynamic stiffness are presented in Tables 8 and 9, respectively. From Table 8, we can see that the identified inertia parameters agree well with those from the swing method.

The change in system dynamic stiffness with frequency in the three directions of its local coordinate system is shown in Figure 12. The modulus of the calculated and the measured FRFs is shown in Figure 13 and verifies the consistency of the identified results. 


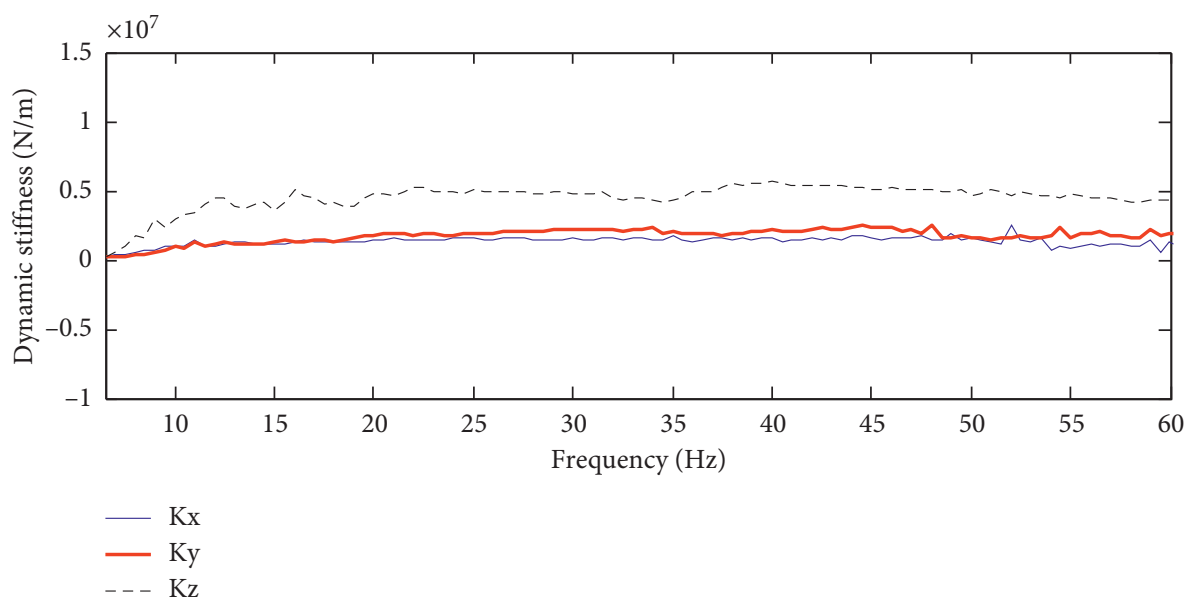

Figure 12: Estimated system dynamic stiffness.

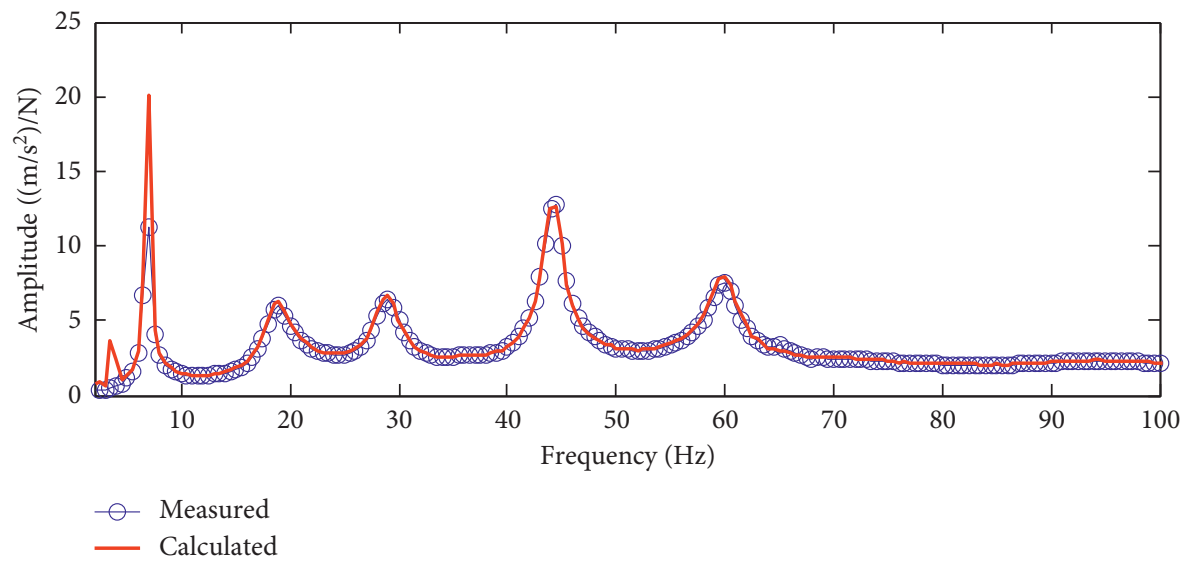

FIGURE 13: Modulus of the measured and calculated FRFs of the engine mount system.

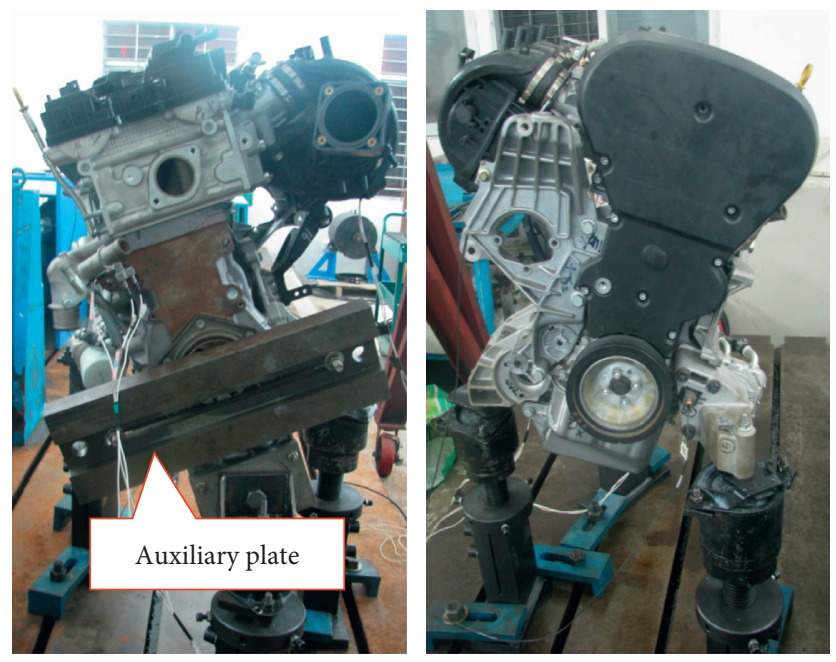

FIGURE 14: Engine with an auxiliary plate.

5.3. Mount Engine with an Auxiliary Plate. Since the mount stiffness is not available, to verify the accuracy of the identified stiffness in Section 5.2, an auxiliary plate $(14.9 \mathrm{~kg})$ was rigidly connected to the engine as shown in Figure 14; then, the same steps were applied to calculate the system dynamic stiffness. If the identified stiffness agrees well with that identified in Section 5.2, the identified results are reliable. The sampling frequency and engine attitude are 


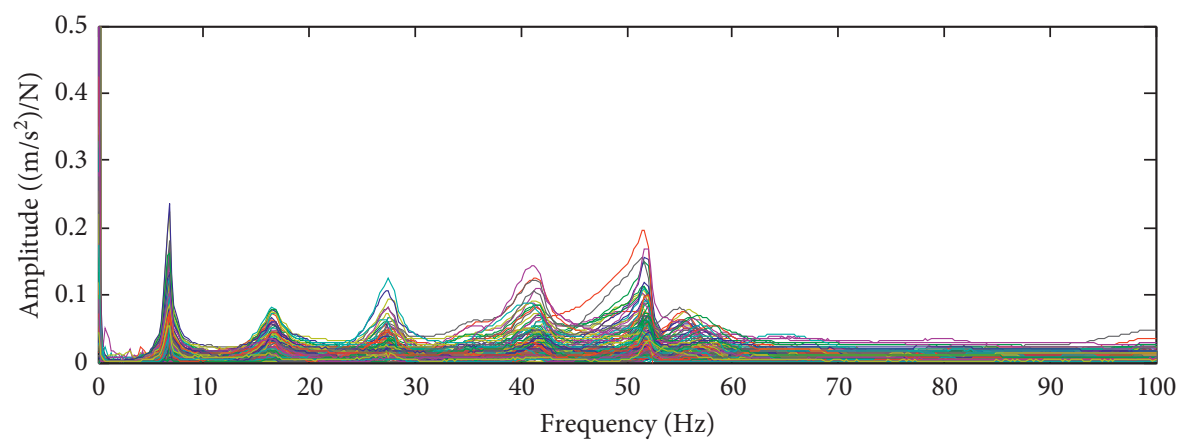

FIGURE 15: FRFs for all measurement points of the engine plate mount system.

TABLE 10: Identified inertia parameters of the engine plate.

\begin{tabular}{lcccc}
\hline \multicolumn{1}{c}{ Inertia parameters } & & Engine plate & Engine & Differences \\
\hline Mass $(\mathrm{kg})$ & $m$ & 126.2 & 110.8 & 19.5 \\
\hline \multirow{3}{*}{ Centre of gravity $(\mathrm{mm})$} & $x_{c}$ & 22.4 & 208.1 & 15.4 \\
& $y_{c}$ & 180.2 & 134.2 & -27.9 \\
& $z_{c}$ & 98.1 & 11.56 & -36.1 \\
Moment of inertia $\left(\mathrm{kg} \cdot \mathrm{m}^{2}\right)$ & $J_{x}$ & 11.46 & 5.61 & -0.1 \\
& $J_{y}$ & 6.57 & 0.01 & -0.04 \\
\hline \multirow{3}{*}{ Product $\left(\mathrm{kg} \cdot \mathrm{m}^{2}\right)$} & $J_{z}$ & 7.97 & 0.34 & 0.63 \\
& $J_{x y}$ & 0.97 & 3.36 & -0.28 \\
\hline
\end{tabular}

TABle 11: Identified system dynamic stiffness of the powertrain mount system.

\begin{tabular}{|c|c|c|c|c|c|c|c|}
\hline & Direction & $x$ & $y$ & $z$ & $\alpha$ & $\beta$ & $\gamma$ \\
\hline \multirow{6}{*}{ System stiffness $(\mathrm{N} / \mathrm{m})$} & $x$ & 1395591.8 & -30449.8 & -942324.2 & -281524.7 & -163269.4 & -374485.9 \\
\hline & $y$ & -113718.0 & 1334671.3 & -681578.8 & 141792.6 & 8774.2 & 210950.1 \\
\hline & $z$ & -525103.2 & -319732.4 & 4847951.0 & 1226340.0 & -643756.5 & 136427.0 \\
\hline & $\alpha$ & -96400.5 & 187465.1 & 1490075.0 & 489962.4 & -255752.3 & 62305.0 \\
\hline & $\beta$ & -342200.5 & 49534.8 & -1123473.9 & -291110.9 & 334301.8 & 83100.4 \\
\hline & $\gamma$ & -398453.2 & 219841.2 & 73853.7 & 83061.1 & 51541.5 & 187883.5 \\
\hline \multirow{6}{*}{ System damp $(\mathrm{N} \cdot \mathrm{s} / \mathrm{m})$} & $x$ & 48323.9 & -1701.9 & -107602.7 & -37387.4 & 21710.4 & -18127.0 \\
\hline & $y$ & -95842.9 & 147080.1 & 44298.3 & 40013.9 & -36403.2 & 35169.6 \\
\hline & $z$ & 109125.4 & -50897.6 & 515109.4 & 138443.2 & -24243.4 & -23883.1 \\
\hline & $\alpha$ & 10866.7 & 21260.1 & 180011.5 & 59125.0 & -7614.7 & 1522.5 \\
\hline & $\beta$ & -83656.9 & 40028.1 & -63065.6 & 1426.8 & 21217.1 & 24798.1 \\
\hline & $\gamma$ & -41526.3 & 25703.9 & -1744.1 & 7179.4 & -7047.3 & 16897.5 \\
\hline
\end{tabular}

TABLE 12: Differences in identified main stiffness between the engine plate and the engine.

\begin{tabular}{lccccc}
\hline Stiffness $(\mathrm{N} / \mathrm{m})$ & $k_{x x}$ & $k_{y y}$ & $k_{z z}$ & $k_{\alpha \alpha}$ & $k_{\beta \beta}$ \\
\hline Engine plate & 1395592 & 1334671 & 4847951 & 489962.4 & 234301.8 \\
Engine & 1490172 & 1910981 & 4635227 & 436581.8 & 222587.3 \\
Differences (\%) & -6.34692 & -30.1578 & 4.589299 & 12.22694 & 5.262879 \\
\hline
\end{tabular}

identical to those in Section 5.2. The measured FRFs calculated for points are presented in Figure 15.

The inertia parameters and system dynamic stiffness identified results are presented in Tables 10 and 11, respectively. Differences between the identified main stiffness are shown in Table 12. In Table 12, the system equivalent stiffness is close, although there is a difference due to the preload. The changes in $K_{x}, K_{y}$, and $K_{z}$ with frequency for the engine with and without the auxiliary plate are shown in Figure 16. The two curves are basically identical in each direction, which verify the accuracy of the identified stiffness. 


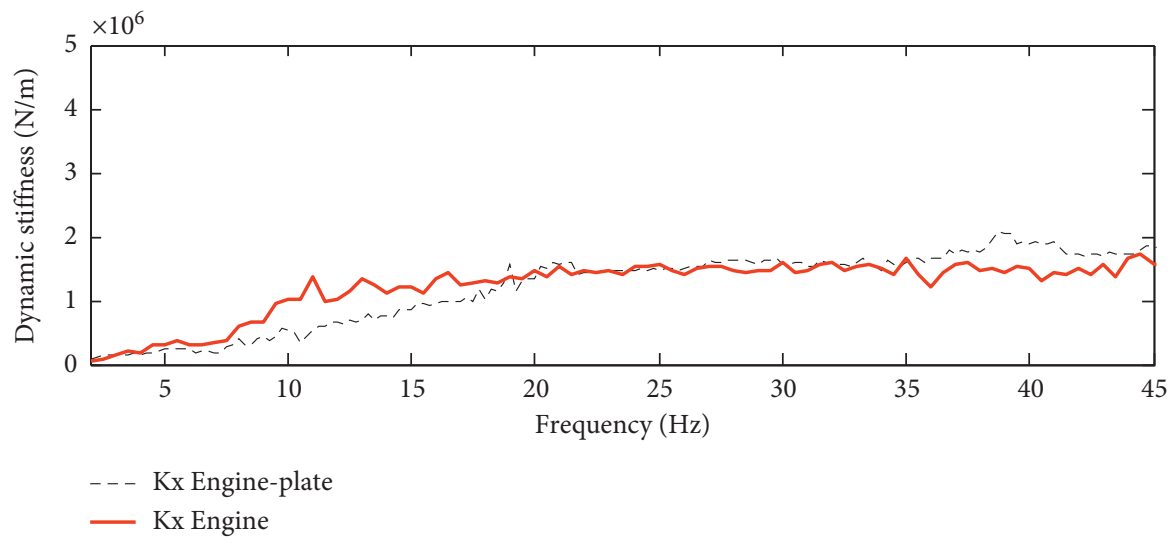

(a)

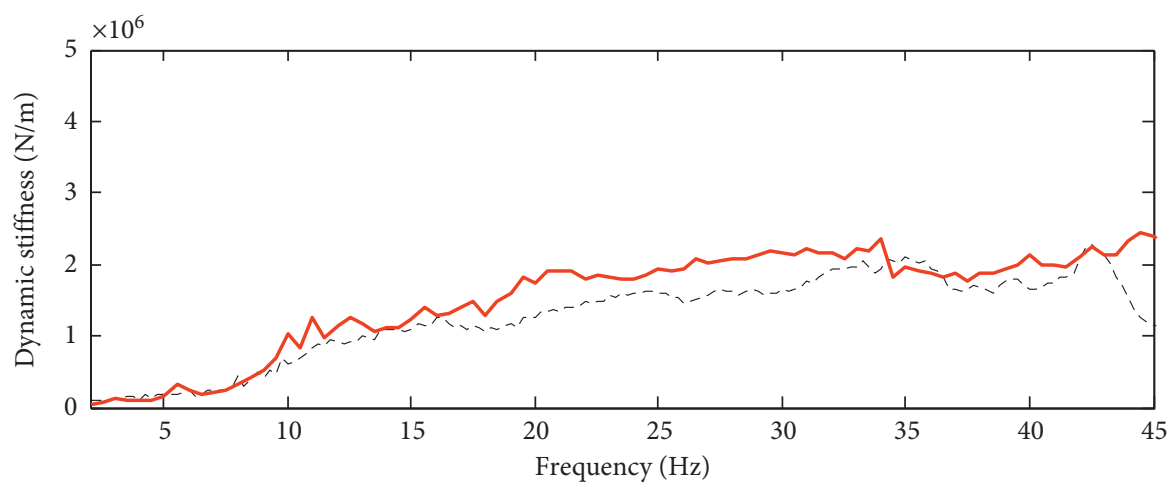

- - Ky Engine-plate

— Ky Engine

(b)

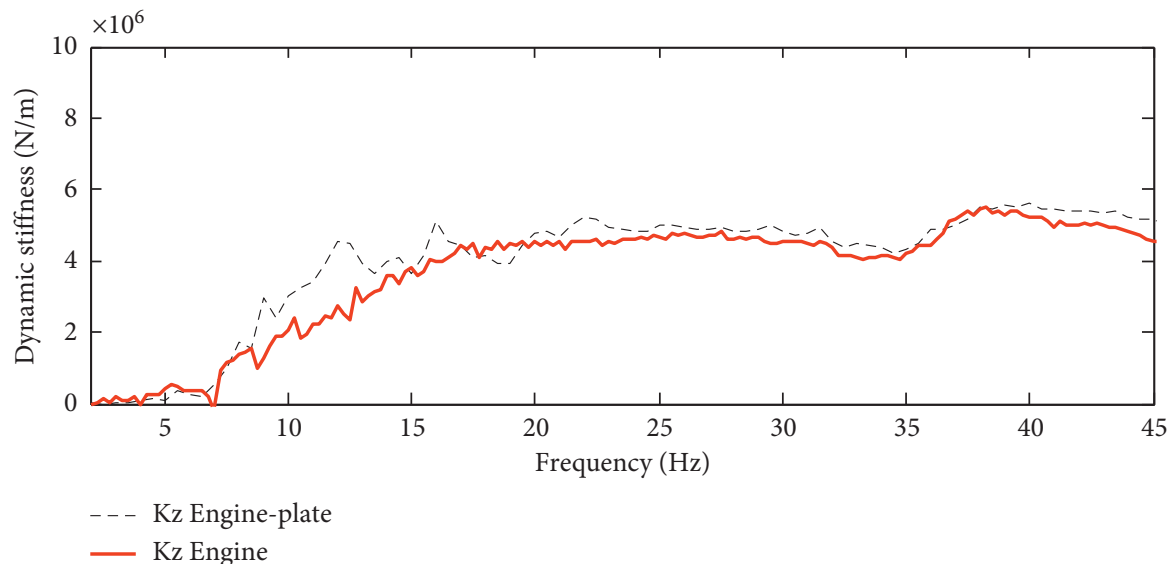

(c)

FiguRe 16: Change in (a) $K_{\mathrm{x}}$, (b) $K_{\mathrm{y}}$, and (c) $K_{\mathrm{z}}$ with frequency.

Table 10 also shows that the identified mass of the engine with the auxiliary plate is $15.4 \mathrm{~kg}$ heavier than that of the engine without an auxiliary plate. The difference in quality is due to the quality of the auxiliary plate $(14.9 \mathrm{~kg})$. Under the effect of the auxiliary plate, the value of the centre of mass of $y_{c}$ and $z_{c}$ should be smaller than that of the engine without an auxiliary plate, and the trend of the identified results is consistent, which verifies the accuracy of the method.

Similar to Section 5.1, the modulus of the calculated FRF is consistent with the measured one in Figure 17, which verifies the consistency of the identified results. 


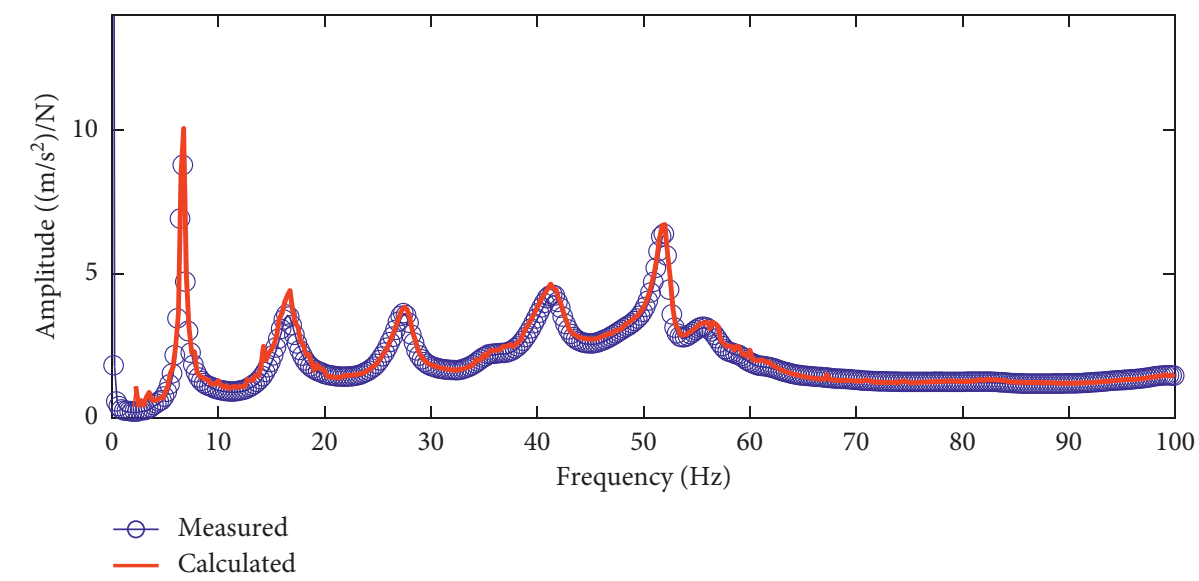

FIGURE 17: Modulus of the measured and calculated FRFs of the engine plate mount system.

\section{Conclusions and Discussion}

An in situ method for identifying ten inertia parameters and system dynamic stiffness of an engine was presented in this paper. Further investigation of the errors of the testing point location effect shows that the coordinates of measuring points should be carefully measured since errors in coordinates lead to errors in results.

The results from the test on the engine supported by the curve bar spring verify the generality of the method, while the results from the test on the engine supported by the mount are comparable to those of a swing test, which indicates the accuracy of the estimation inertia parameter method. The consistency of the identified dynamic stiffness of the engine with and without an auxiliary plate shows that the estimation of the system dynamic stiffness is reliable. In addition, for each experiment, the modulus of all FRFs calculated from the inertia parameters and system dynamic stiffness has high consistent with the measured value, which further verifies the accuracy of the identified results.

However, the system dynamic stiffness identification method can only identify the stiffness at the origin of the coordinates. This method cannot identify the stiffness of each mount. In future research, we will study more appropriate methods to overcome this deficiency.

\section{Data Availability}

The data used in this study are included within the article.

\section{Conflicts of Interest}

The authors declare that they have no conflicts of interest.

\section{Acknowledgments}

This work was supported by the National Natural Science Foundation of China (Grant nos. 51405272, 51505258, and 51975121) and partly supported by the Natural Science Foundation of Shandong Province (ZR2020ME126), the Youth Science and Technology Plan Project of colleges and universities in Shandong Province (Grant no. 2019KJB019),
Shandong Provincial Major Scientific and Technological Innovation Project (2019JZZY020617), the Shandong Provincial Key Research and Development Program (2019GNC106071), and the State Key Laboratory of Mechanical Behavior and System Safety of Traffic Engineering Structures, China (Grant no. 1903).

\section{References}

[1] L. Dan and Z. C. Hou, "Sensitivity analysis of inertial parameters in powertrain mounting design," Automotive Engineering, vol. 29, pp. 884-888, 2007.

[2] P. D. Gaberson and H. A. Gaberson, "Surmounting the inherent errors in the trifilar pendulum measurement of moment of inertia," Journal of the Acoustical Society of America, vol. 54292 pages, 1973.

[3] J. J. Dowling, J. L. Durkin, and D. M. Andrews, "The uncertainty of the pendulum method for the determination of the moment of inertia," Medical Engineering \& Physics, vol. 28, no. 8, pp. 837-841, 2006.

[4] W. B. Shangguan, L. Y. He, and Z. L. Tian, "Development of an equipment for measuring the center of gravity and the moments of inertia of automotive powertrain," Journal of Vibration Engineering, vol. 23, pp. 119-125, 2010.

[5] M. Gobbi, G. Mastinu, and G. Previati, "A method for measuring the inertia properties of rigid bodies," Mechanical Systems and Signal Processing, vol. 25, pp. 305-318, 2011.

[6] H. Hahn, "Inertia parameter identification of rigid bodies using a Multi-Axis test facility," in Proceedings of the Third IEEE Conference on Control Applications, Glasgow, Scotland, August 1994.

[7] S. M. Pandit and Z.-Q. Hu, "Determination of rigid body characteristics from time domain modal test data," Journal of Sound and Vibration, vol. 177, no. 1, pp. 31-41, 1994.

[8] M. R. Ashory, A. Malekjafarian, and P. Harandi, "On the accuracy of estimation of rigid body inertia properties from modal testing results," Structural Engineering \& Mechanics, vol. 35, pp. 1-13, 2010.

[9] R. A. B. Almeida, A. P. V. Urgueira, and N. M. M. Maia, "Identification of rigid body properties from vibration measurements," Journal of Sound and Vibration, vol. 299, no. 4-5, pp. 884-899, 2007.

[10] J. Bretl and P. Conti, "Rigid body mass properties from test data," in Proceedings of the 5th IMAC, pp. 655-659, Sweden, April 1987. 
[11] R. Almeida, Evaluation of the Dynamic Characteristic of Rigid Bodies Based on Experimental Results, PhD Thesis, New University of Lisbon, Lisbon, Portugal, 2006.

[12] H. Lee, Y.-B. Lee, and Y.-S. Park, "Response and excitation points selection for accurate rigid-body inertia properties identification," Mechanical Systems and Signal Processing, vol. 13, no. 4, pp. 571-592, 1999.

[13] J. M. W. Lau and F. Deblauwe, Advanced FRF Based Determination of Structural Inertia Properties, SAE, Chicago, IL, USA, 2008.

[14] W. Leurs, M. Gielen, B. Dierckx, Calculation of Rigid Body Properties from FRF Data: Practical Implementation and Test Cases. LMS, 2000, 1998.

[15] C. Xu, K. Ding, and Z. Yang, "Identification of engine inertia parameters on the basis of Frequency Response Functions," International Journal of Vehicle Design, vol. 60, no. 1/2, pp. 121-137, 2012.

[16] J. A. Mangus, C. Passerello, and C. Vankarsen, "Direct estimation of rigid body properties from harmonic forced responses," in Proceedings of the 15th International Modal Analysis Conference, pp. 175-180, Orlando, FL, USA, July 1997.

[17] M. Link and G. Qian, "Identification of dynamic models using base excitation and measured reaction forces," Revue Francaise de Mecanique, vol. 1, pp. 35-42, 1994.

[18] R. A. B. Almeida, A. P. V. Urgueira, and N. M. M. Maia, "Evaluation of the performance of three different methods used in the identification of rigid body properties," Shock and Vibration, vol. 15, no. 3-4, pp. 467-479, 2008.

[19] Y. Zhang and Z. C. Hou, "Identification of rigid body inertia properties by utilizing modal parameters," Journal of $\mathrm{Vi}$ bration Engineering, vol. 29, pp. 436-443, 2016.

[20] Y. X. He, T. Wang, and L. J. Zhang, "Improved identification method for structural inertial parameters based on FRF," Journal of Vibration and Shock, vol. 38, pp. 236-241, 2019.

[21] O. Vahid, A. Khajepour, F. Ismail, and C. R. Urbaniak, "In situ identification of vehicle engine inertia properties," International Journal of Vehicle Noise and Vibration, vol. 3, no. 1, pp. 46-69, 2007.

[22] J. V. Karsen, D. Johnson, J. Blough, and M. Rao, Estimation of Powertrain Inertia Properties via an In-Situ Method, SAE, Chicago, IL, USA, 2007.

[23] Y. Yu, N. G. Naganathan, and R. V. Dukkipati, "A literature review of automotive vehicle engine mounting systems," Mechanism and Machine Theory, vol. 36, no. 1, pp. 123-142, 2001.

[24] Y. Gao, X. Liu, and J. Xiang, "FEM simulation-based generative adversarial networks to detect bearing faults," IEEE Transactions on Industrial Informatics, vol. 16, no. 7, pp. 4961-4971, 2020.

[25] X. Liu, H. Huang, and J. Xiang, “A personalized diagnosis method to detect faults in gears using numerical simulation and extreme learning machine," Knowledge-Based Systems, vol. 195, Article ID 105653, 2020.

[26] X. Y. Liu, H. Z. Huang, and J. W. Xiang, "A personalized diagnosis method to detect faults in a bearing based on acceleration sensors and a FEM simulation driving support vector machine," Sensors, vol. 20, p. 42, 2020.

[27] Z. He, Powertrain Inertial Parameter Identification Based on Firefly Algorithm, Master's thesis, Wuhan University of Science and Technology, Wuhan, China, 2019.

[28] H. H. Zhang and W. K. Shi, "Model of the secondary path between the input voltage and the output force of an active engine mount on the engine side," Mathematical Problems in Engineering, vol. 2020, Article ID 6084169, 16 pages, 2020.

[29] A. Kumar, C. P. Gandhi, Y. Q. Zhou, R. Kumar, and J. W. Xiang, "Latest developments in gear defect diagnosis and prognosis: a review," Measurement, vol. 158, Article ID 107735, 2020.

[30] E. O. Lu and M. Ripin, "Dynamic stiffness and loss factor measurement of engine rubber mount by impact test," $M a$ terials and Design, vol. 32, pp. 1880-1887, 2011. 